\title{
EL TRATAMIENTO DEL TEMA DE LAS “EDADES DEL MUNDO” EN EL LIBRO II DE LAS HALIÉUTICAS DE OPIANO DE CILICIA ${ }^{1}$
}

JUAN CARLOS IGLESIAS ZOIDO

Dep. de CC. de la Antigüedad, UEX

The objective of this work is the analysis of the "ages of the world" theme by Oppian of Cilicia in book II of his Halieutica. comparing it with the tradition of the previous didactic poetry and with the sociopolitical conditions of his days, when the poem was composed.

0. Las Haliéuticas de Opiano de Cilicia ${ }^{2}$ es el poema didáctico en lengua griega más importante de la época imperial. Compuesto hacia el año 180 d.C., en el final del reinado de Marco Aurelio, se convirtió en una obra que gozó de gran éxito y difusión, influyendo decisivamente en la elaboración de otras composiciones didácticas, como las Cinegéticas de Opiano de Apamea ${ }^{3}$.

1 El presente artículo es el fruto de la reelaboración de la ponencia que pronunciamos (Febrero de 1997) en el marco del Curso de Postgrado (ref.: 206/96) Lenguas Clásicas: Nuevas Perspectivas y Enfoques del Comentario de Textos Greco-Latinos, organizado en Badajoz por el Departamento de Ciencias de la Antigüedad de la UEX.

2 A lo largo del presente trabajo seguimos el texto editado en la colección Loeb por A. W. Mair, Oppian, Colluthus, Tryphiodorus, Londres - Cambridge, 1928. Hay traducción española de C. Calvo Delcán, Opiano: De la caza. De la pesca. Anónimo: Lapidario órfico, Madrid, 1990

3 En la Antigüedad se consideró que ambas obras fueron escritas por el mismo autor, un solo Opiano, cuya vida era bien conocida a través de un artículo de la Suda y de varias biografías, dos en prosa y una en verso, tal y como ha estudiado P. Hamblenne, «La légende d' Oppien», $A C$ 37, 1968, pp. 589-619. O. Mazal, «Eine neue Rezension der Biographie Oppians», WS 80, 1967, pp. 115-124, ha sacado a la luz una nueva Vita, que no se diferencia en lo esencial de las ya conocidas. La crítica moderna ha distinguido el trabajo de dos escritores bien diferentes desde que J. G. Schneider, Oppiani poetae Cilicis de Venatione libri

EMERITA $(E M)$ - Revista de Lingüística y Filología clásica - LXVII 2, 1999 - pp. 263 - 284 
Teniendo en cuenta la tradicional dicotomía establecida en la poesía didáctica entre la búsqueda de instrucción o la búsqueda de deleite ${ }^{4}$, una parte de la crítica ha señalado que Opiano de Cilicia compuso las Haliéuticas con una finalidad moralizante. Esta es la opinión de B. Effe, para quien la obra tendría que ser clasificada dentro de lo que él denomina "tipo transparente" de poema didáctico, es decir, aquel en el que el objeto real de la instrucción no es aquello que constituye la materia del poema - sea la astronomía, la caza o la pesca -, sino la enseñanza de otras cuestiones tomando como excusa el material poetizado. Arato, Virgilio y Opiano de Cilicia son los modelos básicos de este tipo de poema ${ }^{5}$. Otra parte de la crítica, como, por ejemplo, James ${ }^{6}$, opina que la composición de Opiano ha de interpretarse desde el punto de vista de la tradición helenística, en la que el principal objetivo de los poetas didácticos fue componer admirables ejercicios de erudición poética.

Ahora bien, más allá de la dicotomía planteada por la crítica, es preciso,

IV et de Piscatione libri V, Königsberg, 1776, pp. III y ss., y K. Lehrs, «Dissertatio V: De Halieuticorum et Cynegeticorum discrepantia», en Quaestiones Epicae, Königsberg, 1837, pp. 303-324, observaron la disparidad de estilo, métrica y léxico entre ambos poemas. Así, la mayor parte de los estudiosos defiende que, por una parte, hay un Opiano de Cilicia, autor de Haliéuticas, que desarrolló su labor literaria en plena época de los Antoninos, entre el año 177 y el 180 d. C., y que dedicó su poema a Marco Aurelio y a su hijo Cómodo; y que, por otra, hay un Opiano oriundo de la ciudad siria de Apamea, imitador del anterior, y autor de una obra de menor aliento poético sobre la caza, Cinegéticas, compuesta pasado el año $198 \mathrm{~d}$. C. y dedicada a Caracalla.

4 Sobre la poesía didáctica greco-latina en general cf. W. Kroll, «Lehrgedicht», RE XII, 2, 1925, coll. 1842-1857; A. Cox, Didactic Poetry: Greek and Latin Literature, Londres, 1969; S. Koster, Antike Epostheorien, Wiesbaden, 1970; F. Capponi, «Didascalici poeti», en VV. AA., Dizionario degli autori greci e latini, vol. II, Milán, 1990, pp. 623-647; Aa. Vv., Mé $\gamma \alpha$ vímıov. Materiali e discussioni per l'analisi dei testi classici 31, 1993; M. Brioso, «La épica didáctica helenístico-imperial», en J. A. López-Férez (ed.), La épica griega y su influencia en la literatura española, Madrid, 1994, pp. 253-282; P. Toohey, Epic Lessons. An Introduction to Ancient Didactic Poetry, Londres-N. York, 1996.

5 Los otros dos tipos de poema didáctico son, según B. Effe (Dichtung und Lehre. Untersuchungen zur Typologie des antiken Lehrgedichts, Münich, 1977, pp. 26 y ss.), los siguientes: A) Tipo Normal: la forma del poema está al servicio del contenido. Su principal representante es Lucrecio. B) Tipo Formal: la forma ocupa el primer plano. El poeta pretende delectare y no docere. Su máximo exponente es Nicandro. 24-36

A. W. James, «The Honey in the Cup in Oppian and Others», PCPhS 12, 1966, pp. 
a nuestro juicio, analizar la obra de Opiano en el marco de la poesía didáctica greco-latina, tal como, en parte, ya hizo Pöhlman ${ }^{7}$. Este tipo de análisis es imprescindible si queremos conocer con mayor precisión las características de una obra que constituye el resultado de una larga evolución del género. En esa línea, el presente trabajo tiene como objetivo analizar la utilización por parte de Opiano del tema de las "edades del mundo", de profunda raigambre literaria, a lo largo del libro II de sus Haliéuticas, y confrontarlo no sólo con la tradición previa sino también con los condicionantes socio-políticos presentes en el momento en que el poema fue redactado. Este análisis permitirá contemplar el segundo libro de su obra $-\mathrm{y}$, por extensión, el resto del poema- como un exponente de la poesía griega que floreció a lo largo del último cuarto del siglo II d.C., en el final de la fructífera época de los Antoninos. Pero antes de pasar al análisis concreto, parece conveniente recordar, aunque sea de forma somera, las características generales de los poetas griegos de época imperial y su relación con Opiano.

\section{Los poetas griegos de época imperial y sus características generales.}

Las Haliéuticas de Opiano de Cilicia es un poema didáctico que pertenece a un período de la literatura griega, la época imperial, caracterizado por un abrumador dominio de los escritores en prosa. Frente al amplio desarrollo de los géneros poéticos en la época helenística, los autores imperiales manifestaron escaso interés por las formas literarias tradicionales en verso; las mentes más agudas del momento centraron su atención en la filosofía $\mathrm{y}$, sobre todo, en la retórica, dando lugar al movimiento conocido como Segunda Sofística ${ }^{8}$. En todo caso, a pesar de tratarse de un grupo de

7 E. Pöhlmann, «Charakteristika des römischen Lehrgedicht», ANRW I, 3, 1973, pp. 813-901. Una versión abreviada del mismo trabajo se puede encontrar en «Sabiduría útil: el antiguo poema didáctico», Historia de la Literatura Universal: I. El mundo antiguo, Madrid, 1988, pp. 135-162.

8 La obra de fondo es la de W. Schmid, Der Atticismus in seinem Hauptvertreterns von Dionysius von Halikarnass bis auf den zweiten Philostrat, 4 vols., Stuttgart, 1887-96. En general, durante mucho tiempo, predominaron las opiniones negativas con respecto a este movimiento: cf. Schmid-Stählin, Geschichte der griechischen Literatur, 2.2, Münich, 1924, pp. 663-671 y B. A. van Groningen, «General Literary Tendencies in the Second Century A. D.», Mnemosyne 18, 1965, pp. 41-56. Fruto de una nueva valoración es el surgimiento de un amplio interés por esta época de la literatura griega. En este sentido, cf. las obras de B. P. Reardon, Courants littéraires grecs des II et III siècles après J.C., París, 1971; de G. W. 
importancia menor, los poetas de época imperial comparten una serie de características generales ${ }^{9}$ que, en el caso de Opiano, se cumplen en todos sus puntos, haciendo de él un poeta representativo de su tiempo. Esas características son las siguientes: procedencia oriental, movilidad, contrapartida económica u honorífica y erudición.

\subsection{Procedencia oriental.}

Al igual que algunos de los principales autores griegos de época imperial, Opiano procede de las regiones orientales del mundo romano ${ }^{10}$. En concreto, de Cilicia, en Asia Menor, como el mismo poeta declara, al señalar que los dioses lo han alzado para ser delicia y cantor entre los cilicios ${ }^{11}$. Más adelante, concreta la localización de su patria chica al hablar de la ciudad de Corico, famosa por sus barcos ${ }^{12}$. Esta procedencia oriental, confirmada por el mismo autor, es un rasgo compartido con la mayor parte de los poetas del período. Así, Posidipo procede de la Tebas egipcia; Mesomedes es de Creta; Páncrates vio la luz en Alejandría; Quinto parece haber nacido en Esmirna; y egipcios son la mayoría de los poetas de la escuela de Nono, como Trifiodoro, Coluto o Museo; finalmente, el otro Opiano, el autor de Cinegéticas, era oriundo de la ciudad siria de Apamea.

Bowersock (ed.), Approaches to the Second Sophistic, Pennsylvania, 1974 y Hellenism in Late Antiquity, Cambridge, 1990; el volumen del ANRW 2.33.1, 1989, pp. 3-302, con aportaciones de E. Cizek, Sirago, Anderson, Bowie y Steinmetz; el trabajo de G. Anderson, The Second Sophistic: A Cultural Phenomemon in the Roman Empire, Londres-N. York, 1993 y S. Swaim, Hellenism and Empire: Language, Classicism and Power in Greek World, AD 50250, Oxford, 1996.

9 Cf. el estudio de J. Alsina, «Panorama de la épica griega tardía», EClás 16, 1972, pp. 139-167. Un análisis similar, referido en este caso a los poetas egipcios del comienzo de la época bizantina, en A. Cameron, «Wandering Poets: A Literary Movement in Byzantine Egypt», Historia 14, 1965, pp. 470-508.

10 Cf. G. Bowersock, Greek Sophists in the Roman Empire, Oxford, 1969, quien estudia las relaciones entre la sociedad romana y el renovado movimiento cultural griego que surge en el mundo oriental, dirigiendo su mirada a las conexiones íntimas que se producen entre ambas esferas y destacando el importante papel político representado por los sofistas.

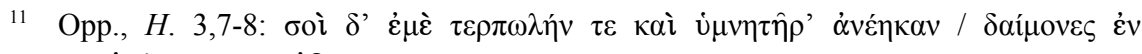

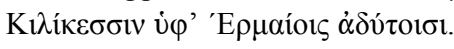

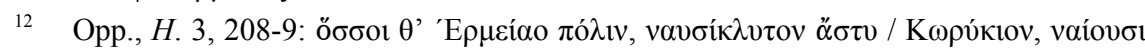

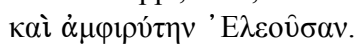


Esta situación no es extraña si se tiene en cuenta el renacimiento económico que vivió la zona asiática del imperio a partir del reinado de Augusto y muy especialmente a lo largo del siglo II d. C., cuando la paz imperial acabó con las exacciones abusivas y con los saqueos en la parte oriental del imperio. Esta nueva situación, favorecida sucesivamente por Adriano (117138), Antonino Pío (131-161) y Marco Aurelio (161-180), propició, en efecto, que las emprendedoras ciudades helénicas de Asia recobraran parte de su antiguo esplendor ${ }^{13}$ y pudieran aportar los medios materiales que habrían de sustentar las nuevas corrientes literarias e intelectuales ${ }^{14}$.

Sin embargo, a finales del siglo II, en el momento en el que Opiano desarrolla su labor poética, a lo largo de gran parte del reinado de Marco Aurelio, asistimos al final de este período de prosperidad a causa de las guerras exteriores y del desequilibrio entre ingresos y gastos ${ }^{15}$. De hecho, a partir de la década de los setenta, fecha de composición del poema, el sistema comienza a resquebrajarse, lo que pensamos que también se percibe en la obra de Opiano.

\subsection{Movilidad.}

Alejados de los centros de poder, como consecuencia de su origen oriental, los poetas de época imperial se caracterizan por su movilidad a lo largo del mundo romano en busca de mecenazgo y protección. Ya los poetas helenísticos, como es bien sabido, realizaron frecuentes viajes en busca de protectores y mecenas. Estas condiciones, aunque cambiaron considerablemente a lo largo de la época imperial, siguieron manteniéndose al menos en dos casos: en el de los maestros de retórica, que recorrían las regiones imperiales dando conferencias y abriendo improvisadas escuelas; y en el de los

13 Cf. al respecto el magnífico análisis sobre la época en general, y sobre la parte oriental del imperio en particular, de A. Boulanger, Aelius Aristide et la sophistique dans la province d'Asie au II siècle de notre ère, París, 1923 (= París, 1968), pp. 1-19. Asimismo, cf. A. D. Macro, «The Cities of Asia Minor under the Roman Empire», ANRW II, 7,2 1980, pp. 687 ss.

14 Sobre la creación literaria durante el reinado de M. Aurelio, cf. el artículo de A. S. S. Farqharson, «Literature of the Age», en D. A. Rees (ed.), Marcus Aurelius: His Life and his World, Oxford, 1951, pp. 89-121. M. Grant ofrece una visión de conjunto de los autores griegos y romanos de la época antonina en su obra The Antonines. The Roman Empire in Transition, Londres-N. York, 1994, pp. 83-127.

15 Cf. R. Rémondon, La crisis del Imperio Romano de Marco Aurelio a Anastasio, Barcelona, 1984. 
poetas profesionales, que iban a la búsqueda de mecenas que financiaran su labor poética. Quizás el ejemplo más extremo sea el de Claudio Claudiano, poeta nacido en Alejandría a finales del siglo IV d. C., que alcanzó en Roma sus más importantes éxitos, escribiendo en latín elogios de las gestas de sus protectores ${ }^{16}$.

En el caso concreto de Opiano, la movilidad parece obedecer, de entrada, a una cuestión más personal. Así, entre los datos biográficos transmitidos por la Suda y por sus Vitae, se destaca el hecho de que uno de los dos Opianos era hijo de Agesilao, un varón distinguido y erudito que tuvo que abandonar su ciudad natal por un desplante hecho al emperador Septimio Severo, sufriendo por ello el destierro en una isla del Mediterráneo ${ }^{17}$. Pues bien, Opiano, años más tarde, ya con su obra poética bajo el brazo, emprendió camino hacia Roma con la intención de conseguir para su padre, según cuentan sus biógrafos, el perdón y la posibilidad de regresar a su patria. Sin embargo, más allá de las informaciones contradictorias que nos ha legado la antigüedad sobre tal peripecia vital ${ }^{18}$, lo cierto es que, teniendo en cuenta sus precedentes en la literatura romana - especialmente en el caso de Virgilio y su relación con Augusto -, pensamos que el viaje a Roma de Opiano de Cilicia y la relación con Marco Aurelio hay que ponerlos en relación más bien con el papel decisivo que desempeña la figura del princeps en la poesía didáctica del momento ( $\mathrm{o}$, incluso, la del rétor en la administración del estado) que con el loable y meritorio deseo de obtener el perdón para su progenitor.

\subsection{Profesionalización.}

Los poetas y rétores que encandilaban a la sociedad del momento conciben su tarea como un quehacer por el que reciben una contrapartida honorífica o económica. En este sentido, consideramos que el poema de Opiano es la típica obra de un autor provinciano deseoso de hacerse un nombre en la capital del Imperio. El autor dedica el poema a Marco Aurelio, aprovechan-

16 Cf. R. Keydell, Claudian. Poetry and Propaganda at the Court of Honorius, Oxford, 1990.

17 Para una explicación histórica del suceso teniendo en cuenta la importancia de la llegada del emperador a una ciudad, cf. F. Gascó, «Septimio Severo en Anazarbo», EMERITA 60, 1992, pp. 235-239.

18 De hecho, la Suda nos informa de que Opiano fue recompensado por Marco Aurelio, mientras que las Vitae en prosa I y II informan que el benefactor fue Caracalla . 
do el apogeo cultural de la época de los Antoninos y el vivo interés que el emperador había manifestado por la poesía griega ${ }^{19}$. Los resultados no se hicieron esperar según cuenta la Suda: la labor poética de Opiano fue muy generosamente pagada, recibiendo una moneda de oro por cada hexámetro.

\subsection{Erudición.}

Los poetas de época imperial son, como lo habían sido sus lejanos antecedentes helenísticos, eruditos. Sus obras muestran un detallado conocimiento de los giros, la lengua y el metro de toda la milenaria tradición griega, lo que no habría sido posible sin un estudio minucioso de la poesía helena anterior. La consecuencia inmediata es que estos poetas manejaron un vocabulario de una enorme riqueza, procedente, en su mayor parte, de la lengua literaria tradicional, que se apartaba cada vez más, incluso en pronunciación y acento, del lenguaje cotidiano. Pues bien, Opiano de Cilicia se muestra como un maestro no sólo en el uso correcto de ese vocabulario, sino también, como ha estudiado James ${ }^{20}$, en la amplia y característica acuñación de neologismos sobre todo adjetivos y verbos compuestos - a partir de términos ya conocidos de la tradición literaria. De manera complementaria, en el ámbito de la métrica, Wifstrand ${ }^{21}$ ha demostrado que Opiano respetaba escrupulosamente las reglas de la cesura calimaquea y que, con su exacta utilización del hexámetro, superó claramente al autor de las Cinegéticas. Todos estos aspectos nos revelan que Opiano era un poeta docto, que conocía muy bien la tradición literaria previa.

1. Teniendo en cuenta las cuatro características señaladas, los poetas griegos de época imperial siguieron dos caminos creativos diferentes: la mayor parte, continuando el legado de Calímaco, fueron epigramatistas, cultivadores de la poesía breve, alusiva e ingeniosa que llena las páginas de la Antología Palatina $^{22}$; sin embargo, un segundo grupo de autores, en abierta competen

19 Cf. H. 1, 1-3. Cf. F. Millar, The Emperor in the Roman World, Londres, 1977, p. 83 y ss., quien analiza la Roma de los Antoninos como un lugar en el que un autor, sobre todo un sofista, podía medrar, ver apreciado su arte y alcanzar el favor (amicitia) del emperador.

20 A. W. James, Studies in the Language of Oppian of Cilicia, Amsterdam, 1970.

21 A. Wifstrand, Von Kallimakos zu Nonnos. Metrisch-stilistische Untersuchungen zur späteren griechischen Epik und zu verwandten Gedichtgattungen, Lund, 1933.

22 Una selección de esta poesía puede leerse en N. Hopkinson, Greek Poetry in the Imperial Period. An Anthology, Cambridge, 1994. Sobre la poesía en Asia Menor en el siglo II 
cia con los escritores de manuales en prosa, se dedicó a elaborar amplias composiciones didácticas. Ahora bien, ¿qué motivos empujaron a un creador como Opiano a seguir esta segunda línea? Pensamos que hay dos: en primer lugar, como comprobaremos en la siguiente sección, al hecho de que la poesía didáctica gozaba de gran aceptación en el mundo romano; en segundo lugar, porque, gracias a esos precedentes romanos, sobre todo Virgilio, el poema didáctico se había convertido en un medio de mostrar la valía poética, a la vez que permitía practicar una poesía cercana al poder.

2. Un ejemplo representativo del modo de proceder de Opiano lo observamos precisamente en su tratamiento del tema de la justicia y de las edades del mundo presente en el libro II, en el que pensamos que hay una perfecta integracion entre forma ${ }^{23}$ (a través de un motivo literario de larga tradición) y contenido $^{24}$ (una selección de información científica de tipo ictiológico proporcionada por sus fuentes en prosa), en el marco de los nuevos condicio-

d.C., cf. Boulanger, ob. cit., pp. 42-47. Una revisión bibliográfica hasta 1929, en R. Keydell, «Die griechische Poesie der Kaiserzeit (bis 1929)», JAW 230, 1931, pp. 41-161 (= Kleine Schriften, Leipzig, 1982, pp. 73-194); cf. sobre las Haliéuticas, en concreto, pp. 44-52 (=9684). Sobre la poesía en la época de los Antoninos, cf. E. L. Bowie, «Greek Poetry in the Antonine Age», en D. A. Russell (ed.), Antonine Literature, Oxford, 1990, pp. 53-90.

${ }_{23}$ Sobre el origen del tema de las edades cf. H. Baldry, «Who invented the Golden Age?», CQ, 1962, pp. 83-92, J. Fontenrose, «Work, Justice and Hesiod's Five Ages», CPh 69, 1974, pp. 1-16 y M. L. West, Hesiod: Works and Days, Oxford, 1978, pp. 172-177, con especial referencia a otros testimonios orientales del mito. Un ensayo de análisis estructural en J. P. Vernant, Mito y pensamiento en la Grecia Antigua, Barcelona, 1973, pp. 21-88. Un análisis actualizado sobre el tema de las edades del mundo en la literatura greco-latina en las obras de J. P. Brisson, Rome et l'âge d' or. De Catulle à Ovide. Vie et mort d'un mythe, París, 1992 y H. F. Bauzá, El imaginario clásico. Edad de Oro, Utopía y Arcadia, Santiago de Compostela, 1993, pp. 21-55.

24 M. Wellmann, «Alexander von Myndos», Hermes 27, 1891, pp. 481-566 y «Leonidas von Byzanz und Demostratos», Hermes 30, 1895, pp. 171-176, estudió las fuentes en prosa seguidas por Opiano, entre las que se encuentran los escritos del ictiólogo Leónidas de Bizancio y el Sobre los animales de Alejandro de Myndos. R. Keydell, «Oppians Gedicht von der Fischerei und Aelians Tiergeschichte», Hermes 72, 1937, pp. 411-434, dejó claro que Eliano parafraseó parte del libro I de Haliéuticas. Y, en esta misma línea, J. A. Richmond, Chapters of Greek Fish-Lore (Hermes Einzelschriften Heft 28), Wiesbaden, 1973, ha analizado con extremo detalle las evidentes relaciones con el De sollertia de Plutarco, por un lado, y con la $H^{a}$ de los animales de Eliano, por otro. En consecuencia, parece claro que, aunque la forma poética fuera su aportación más importante, la obra de Opiano se insertó en el marco de una tradición científica, en donde actuó como medio transmisor de conocimientos e ideas. 
nantes políticos y sociales.

2.1. El libro II cierra la primera parte ${ }^{25}$ de las Haliéuticas. En él, tras un

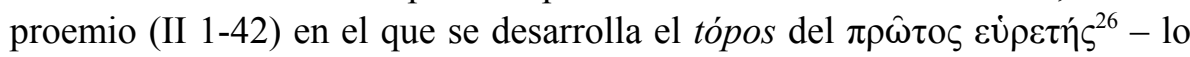
que permite presentar a diversos dioses como los creadores de tareas y funciones vitales para los hombres (II 3-32) -, Opiano describe (II 43-663) la enemistad entre los animales marinos y su cruenta lucha por la supervivencia $^{27}$. En claro contraste con ello, el autor termina con una breve exposición (H. II 642-663) dedicada a describir, como caso excepcional, el manso y

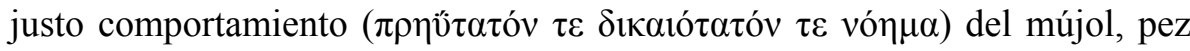
que no perjudica a ninguno ni de su especie ni de otra ${ }^{28}$. Esta amplia sección

25 Opiano desarrolla lo que Pöhlmann, art. cit., pp. 852 ss. denomina «forma ampliada del poema didáctico». La mayor parte de las obras didácticas griegas, siguiendo el modelo hesiódico, estructuraba el tema tratado en un solo libro, con un ordenación interna mediante simples asociaciones de ideas. Frente a esta situación, vigente hasta la obra de Dionisio Periegeta, el De rerum natura lucreciano estableció un segundo modelo más complejo compuesto por varios libros. El desarrollo de este modelo, con la consiguiente expansión del contenido, obligó a los poetas didácticos a prestar una mayor atención a la estructura interna. Así ocurre con Opiano, que, en busca de éxito, adopta una característica propiamente romana, elaborando una obra de gran complejidad formal, con una estructura muy cuidada, compuesta por dos partes claramente diferenciadas: la primera (libros I-II) estudia la vida y hábitat de los peces, y la segunda (libros III-V) se centra en el arte de la pesca: tras pasar revista a los atributos con que ha de contar el buen pescador en comparación con el cazador, el poema describe cómo son capturados diversos tipos de peces y acaba con una loa a la superioridad del hombre sobre los animales marinos. Análisis detallados de esta estructura se encuentran en R. Keydell, «Oppianos», RE XVIII, I, coll. 698-703; G. Munno, «La Pesca di Oppiano: analisi ed appunti», RFIC 50, 1922, pp. 307-334; Pöhlmann, art. cit., pp. 852 ss.; y Effe, ob. cit., pp. 137 ss.

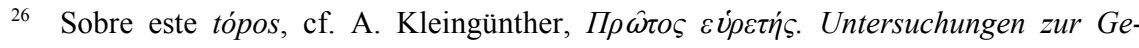
schichte einer Fragestellung, (Philologus Suppl. 26/1), Berlín, 1934.

27 En este sentido una de las secciones más trabajadas del libro II es aquella en la que Opiano describe la enemistad recíproca entre el pulpo, la murena y la langosta (II 253-421), lo que le permite elaborar una estructura en anillo en la que el símil juega un papel destacado: Transición / Introducción: II 253-257

I) Pulpo y Murena (II 258-320): a) Comparación con luchadores (II 277-281) || b) Comparación con ciervos y serpientes (II 289-294) || c) Comparación con el niño botín de guerra (II 313-320).

II) Murena y Langosta (II 321-388): a) Comparación con un capitán (II 326-330) || b) Comparación con cazador de fieras (II 350-356) || c) Comparación con erizo y serpientes (II 359386).

III) Langosta y Pulpo (II 389-418): a) Comparación con un ladrón (408-418).

Transición / final: II 419-421.

28 El contraste entre el modo de vida del mújol, que le hace acreedor de un honorable 
del poema ${ }^{29}$ se encuentra claramente enmarcada por un prólogo (II 43-45), en el que se introduce la cuestión - «Entre los peces no hay justicia ni respeto dignos de ser tenidos en cuenta» -, y un epílogo (II 664-689), donde el poeta resume todo lo tratado. Pasemos a ver ambos textos. En el primer caso, nos encontramos ante tres versos que introducen la cuestión mediante

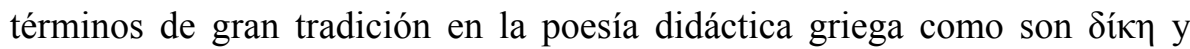
$\alpha i \delta \omega \varsigma^{30}$ (Opp., H. II 43-45):

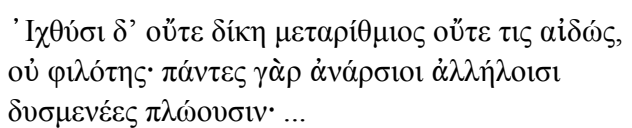

Entre los peces ni la justicia, ni el respeto ni la amistad son tenidos en cuenta: todos nadan entre sí con ánimo hostil ${ }^{31}$.

En el segundo caso, el poeta resume el contenido desarrollado a lo largo del libro II y lo reinterpreta, comparándolo con la especie humana, a través de la introducción del tema de las edades del mundo (Opp., $H$. II 664-689):

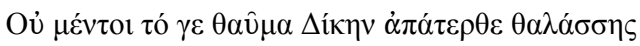

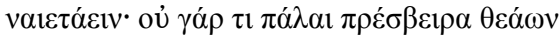

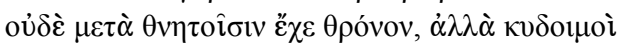

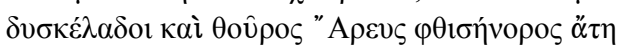

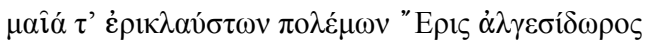

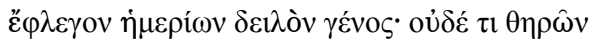

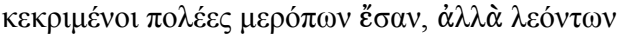

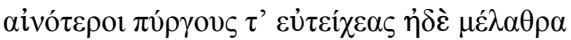

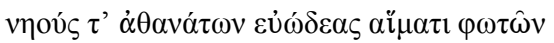

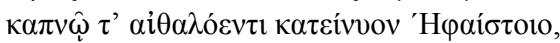

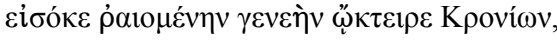

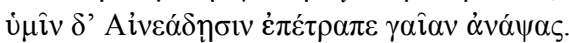

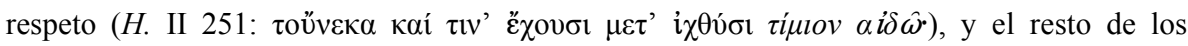

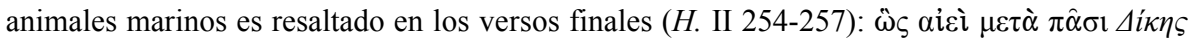

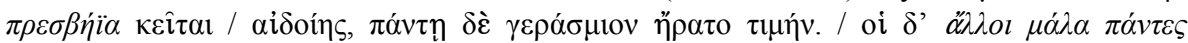

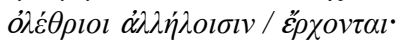

29 Los dos elementos desarrollados son adelantados en el proemio de la obra (H. I 1-12), en donde se lleva a cabo un resumen del contenido general del poema. En concreto, el verso 6

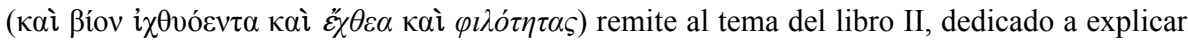
sus enemistades ( $\dot{\varepsilon}^{\prime} \chi \varepsilon \varepsilon \alpha$ ) (II 43-641) y, en mucha menor medida, su buen entendimiento (

30 Como señala C. García Gual, «El mito de las edades», en Introducción a la mitología griega, Madrid, 1992, p. 111, «Aidos y dike son los fundamentos de la convivencia política, según destaca también Platón - en su versión del mito de Prometeo en su Protágoras.»

31 Las traducciones son nuestras. 


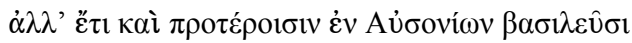

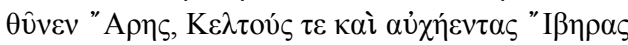

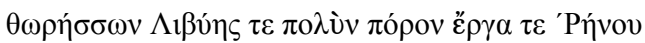
"I

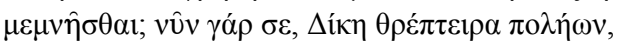

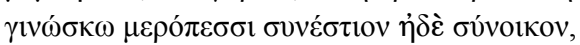

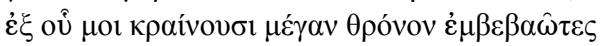

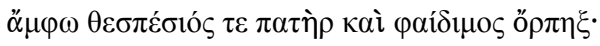

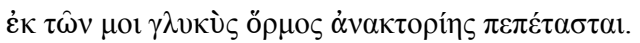

Con todo, no debe llamar la atención que Justicia habite lejos del mar, cuando no ha mucho que ella, la más augusta entre las diosas, ni siquiera ocupaba un trono entre los mortales, sino que los tumultos de sonido terrible y la impetuosa locura de Ares, destructor de hombres, y la Discordia, pródiga en dolores, madre de la guerra que tanto llanto, arrasaban la desgraciada raza de los mortales. Y cuando tampoco eran muchos los mortales que se diferenciaban de las bestias salvajes, sino que, más fieros que leones, cubrían las torres bien amuralladas y las moradas y los aromáticos templos de los inmortales con la sangre de los hombres y con el humo oscuro de Hefesto; hasta que el Crónida se apiadó de la desgarrada raza y, ofreciéndosela a vosotros, hijos de Eneas, os encomendó la dirección de la tierra. Pero, incluso entre los reyes anteriores de los Ausonios, se enfurecía Ares, levantando en armas a los celtas y a los orgullosos iberos y la gran extensión de Libia y los dominios del Rin, y al Istro y al Éufrates. Pero, ¿por qué acordarme de estos hechos de la lanza? Pues observo que ahora, tú, Justicia, sustentadora de ciudades, compartes el hogar y la morada con los mortales desde que me gobiernan, alzados en un gran trono, ambos, el excelente padre y el espléndido retoño, gracias a cuyo gobierno está abierto para mí un dulce puerto.

2.2. De entrada, como es evidente, nos encontramos en estos pasajes - sobre todo en el primero - ante un eco de los famosos versos de Trabajos $^{32}$ en los que Hesíodo recomienda a Perses obedecer a la justicia y no actuar con la fuerza bruta como las bestias salvajes, siguiendo la norma dictada por el Crónida. Hesíodo llegaba a la conclusión de que «no existe justicia entre los animales». Este mismo aspecto, partiendo seguramente de un comentario de la misma fuente, es también tratado por Plutarco en De sollertia animalium $(964 \mathrm{~B})^{33}$ y por Eliano (VI 50) ${ }^{34}$, si bien, en este caso se pone en relación con

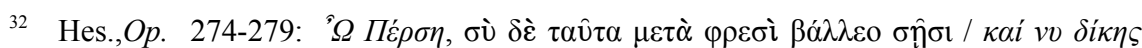

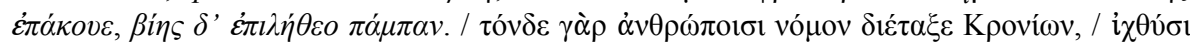

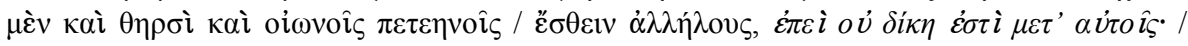

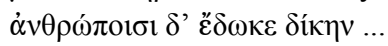

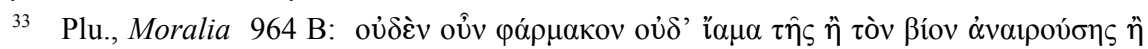

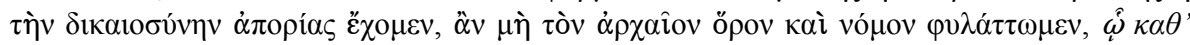

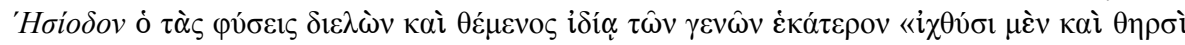

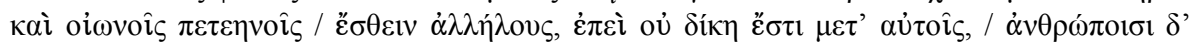


la debatida cuestión de la inteligencia de los animales. Tanto Plutarco anterior a Opiano - como Eliano - posterior a él - llegan a la conclusión de que sí existe justicia entre los animales terrestres y que, en todo caso, la afirmación hesiódica sólo tendría validez entre los animales marinos. Pues bien, este último aspecto, que cuenta con una clara tradición, es el que precisamente ha servido a Opiano para estructurar el libro II de su poema.

2.3. En todo caso, la utilización de este lugar común por parte de Opiano va mucho más allá de un simple uso de las fuentes en prosa y debe ser relacionado con la tradición poética anterior. Así, el tema de la justicia es uno de los más importantes que desarrolla Hesíodo no sólo en Trabajos, sino también en Teogonía, donde, al vencer Zeus a Cronos y a los Titanes, se implanta un orden nuevo, del que el Crónida es el valedor. Ahora bien, teniendo en cuenta el epílogo de Opiano ${ }^{35}$ y las conclusiones a las que pretende llegar, los puntos de contacto con la tradición poética previa tienen que ver sobre todo con uno de los aspectos más importantes del tema de la justicia en el mundo: el llamado mito de las edades del mundo, que gozó de gran desarrollo en la poesía didáctica greco-latina:

a) Hesíodo, en Trabajos, introduce el mito de las cinco edades ${ }^{36}$, en el que cada raza es reemplazada enteramente por otra y donde el autor predice que, al final de la edad de hierro, debido a la degradación producida, Aiঠós y Nér $\varepsilon \sigma ı \varsigma$ marcharán al cielo ${ }^{37}$.

b) Arato retoma la idea de la justicia abandonando la tierra en su versión del

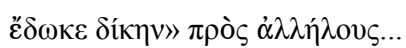

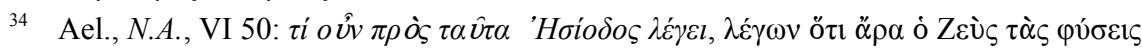

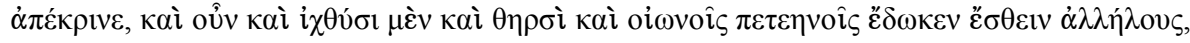

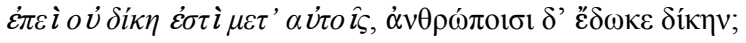

35 M. Brioso, «Los proemios en la épica griega de época imperial», en M. Brioso - F. J. González (edd.), Las letras griegas bajo el imperio, Sevilla, 1996, pp. 53-133, al respecto describe (p. 103 ss.) un epílogo «extenso (II 664-683), en el que el tema de la violencia entre los peces conduce al motivo tradicional de la personificada $\Delta$ ík $\eta$ entre los humanos, cuya conquista culmina, como era de esperar, bajo el cetro de los soberanos elogiados».

36 Según Fontenrose, art. cit., el mito sería para Hesíodo un aǐtıov con el que explicar la necesidad de trabajar para vivir. Para Arato y sus seguidores, en cambio, el declive moral de las razas es una de las características primarias del mito.

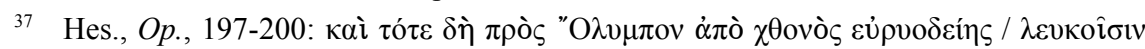

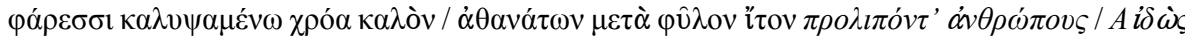

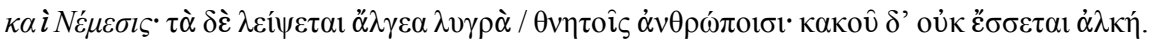


mito de las edades, mito que en Arato también consiste en una progresiva degradación de la raza humana, en la que la edad de plata es vástago de la de oro, y la de bronce es vil descendiente de la de plata. Es en la edad de plata donde dan comienzo las disputas entre los hombres, razón por la cual $\Delta$ íkך se retira a la cima de una montaña. Al agravarse las discordias en la edad de bronce, la diosa $\Delta$ íkn se elevó al cielo para convertirse en una constelación ${ }^{38}$.

c) Esta visión pesimista de la degradación progresiva de la raza humana y el alejamiento de la justicia es una idea compartida por los poetas romanos ${ }^{39}$. Así, Lucrecio considera que el incremento de las guerras y de la decadencia moral se deben a una culpa innata en el ser humano, preocupado sólo por el oro y la púrpura $^{40}$. Por su parte, Catulo termina su carmen 64 con una descripción de la edad de hierro, señalando su convencimiento de que la tierra arrastra una mancha de generación en generación que hace inevitable su deterioro $^{41}$. Ovidio, en Metamorfosis I 89-150, retoma el mito de las edades, con una progresión decadente a lo largo de cuatro edades - oro-plata-broncehierro - que supone una vuelta al modelo descrito por Hesíodo.

d) Frente al planteamiento desarrollado por estos poetas, Virgilio, según ha estudiado Johnston ${ }^{42}$, supone un cambio sustancial: En primer lugar, frente a una visión marcada por el pesimismo, que habla de una edad áurea situada en un pasado mítico irrecuperable, Virgilio muestra la posibilidad de retornar a

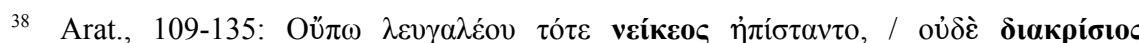

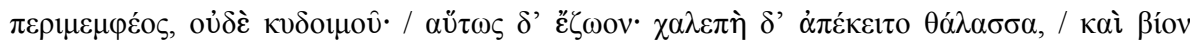

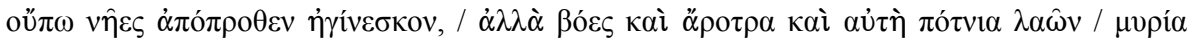

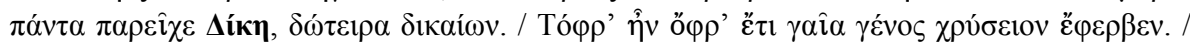

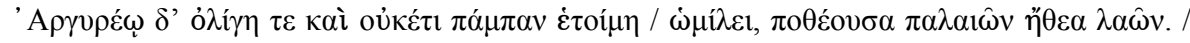

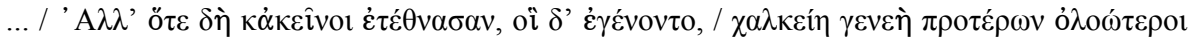

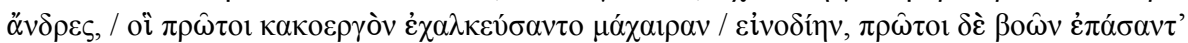

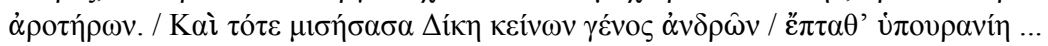

39 Un catálogo y análisis detallado de los pasajes en B. Gatz, Weltarter, goldene Zeit und sinnverwandte Vorstellungen, Hildesheim, 1967, pp. 144-165. En nuestro caso citamos sólo algunos de los ejemplos más significativos.

40 Lucr., V 1423-5: tunc igitur pelle, nunc aurum et purpura curis / exercent hominum uitam belloque fatigant; / quo magis in nobis, ut opinor, culpa resedit.

41 Catull., 64, 397-9 y 405-6: Sed postquam tellus scelere est imbuta nefando, / iustitiamque omnes cupida de mente fugarum, / perfudere manus fraterno sanguine fratres ... / omnia fanda nefanda malo permixta furore / iustificam nobis mentem auertere deorum.

42 P. A. Johnston, Vergil's Agricultural Golden Age. A Study of the Georgics, Leiden, 1980, pp. 41 ss. 
una edad de oro en el caso de que se den las circunstancias adecuadas ${ }^{43}$. Así, sobre todo en la égloga $\mathrm{IV}^{44}$, elaborada hacia el año 40 a. de C., reemplaza la tradicional línea cronológica por un modelo de renovación periódica, en el que, además, el número tradicional de razas ha quedado reducido al binomio hierro/oro. Esta visión de una posible nueva edad de oro, por medio del nacimiento de un niño, es algo que sucede por primera vez en toda la tradición greco-romana. De modo que Virgilio señala que $\Delta$ íkך vuelve de nuevo a la tierra, utilizando la figura astral de Arato (IV 6 iam redit et Virgo), con lo que definitivamente quedarán abolidos la discordia y todo aquello que caracteriza a la gens ferrea ${ }^{45}$.

En segundo lugar, con Virgilio se produce el paso de un ámbito mítico a otro real y contemporáneo. Mientras que uno de los rasgos más significativos de la edad de oro transmitida por la tradición poética era su ubicación en un ámbito ideal, Virgilio traslada el mito al plano político para hacer coincidir la aurea aetas con la figura de Augusto. De hecho, el contexto temporal de la égloga IV es el año 40 a. de C., durante el consulado de A. Polión, con motivo del Pacto de Brindisi entre Antonio y Octavio. Y ese niño, en quien S. Agustín creyó ver al propio Jesucristo anunciado proféticamente por Virgilio ${ }^{46}$, sería el fruto del matrimonio entre Antonio y la hermana de Augusto, con el que se resolvería su rivalidad. Más tarde, en las Geórgicas, Virgilio ya identifica directamente la aurea aetas con el gobierno de Augusto, a quien llega a invocar como "decimotercer dios" $"$ Y en la Eneida VI 791 y ss., en palabras de Anquises, se predice la llegada de Augusto César, quien fundará en el Lacio los aurea saecula.

43 Virgilio desarrolla el mito de las edades también en Georg. I 125; II 536 y 538; Aen. VIII 319-320.

44 Verg. Eg. 4, 5-10: magnus ab integro saeclorum nascitur ordo. / iam redit et Virgo, redeunt Saturnia regna, / iam noua progenies caelo dimittitur alto. / Tu modo nascenti puero, quo ferrea primum / desinet ac toto surget gens aurea mundo, / casta faue Lucina: tuus iam regnat Apollo.

45 Un resumen de las principales interpretaciones - cristianas, neopitagóricas, historicistas - y de la amplísima bibliografía suscitada por la Égloga IV en W. Kraus, «Vergils vierte Eklogue» y S. Benko, «Virgil's Fourth Eclogue in Christian Interpretation», en ANRW II, 31,1, 1982, pp. 604-645 у 646-705

46 Cf. Aug., Epist. 137, 12. Cf. G. Highet, La tradición clásica, Méjico, 1954, vol. I, p. 122.

47 Cf. Georg. I 5-42. Cf. también Georg. III 13, donde promete erigirle un templo de mármol. 
2.4. Por su parte, teniendo en cuenta esta tradición previa, consideramos que Opiano sigue la línea emprendida por Virgilio en el tratamiento de este motivo literario. De hecho, la estructuración de todo el libro II de las Haliéuticas está elaborada según las pautas del autor de la Eneida, al trasladar el mito tradicional de las edades del mundo al plano político. Así, tras haber introducido al comienzo del libro II el tópico hesiódico de la falta de justicia en el mundo de los peces, en el epílogo reinterpreta todo lo tratado bajo los nuevos parámetros virgilianos. En primer lugar, el mito de las razas queda reducido al mismo binomio hierro/oro expresado por Virgilio. Frente a la raza que sufría la «impetuosa locura de Ares» y la «discordia pródiga en dolores», los hombres actuales viven en una época dominada por la Justicia. En segundo lugar, Opiano, para que no quede ninguna duda sobre la identificación de la nueva edad dorada, procede a concretarla de un modo que afecta tanto al plano espacial como al temporal:

a) Plano temporal. Opiano mantiene una postura optimista frente a la pesimista defendida por la tradición previa a Virgilio, al manifestar que es posible la llegada de una nueva edad de oro tras un período en el que falta la justicia y en el que los hombres no se diferencian de las bestias (II 269-270). Evidentemente, esta ubicación de esa nueva aurea aetas en un presente histórico perfectamente definido, que es regido por el emperador antonino al que se ha dedicado el poema, sigue la estela de la actitud de Virgilio con respecto a Augusto - acorde con la perspectiva latina que adecua el mito a la historia -, y, sobre todo - lo que creemos que es fundamental - muestra a las claras la intencionalidad política del pasaje analizado en concreto (que va más allá de la simple lisonja y alabanza del poder imperial) y del libro II en general. Esta nueva época de paz a la que se hace referencia cuenta con un precedente de época augústea de tal calibre en la tradición poética que su inclusión y desarrollo en la obra del poeta de Cilicia, al final del siglo de los Antoninos, ha de obedecer a razones afines a las que motivó su empleo por parte de Virgilio.

b) El ámbito de referencia espacial pasa del territorio impreciso del mito al mundo romano contemporáneo. Así, Opiano cuenta que, tras el período de brutalidad, la Edad de hierro en la que los hombres actuaban como bestias salvajes, el Crónida se apiadó de los hombres y envió precisamente a los hijos de Eneas para conservar su raza (II 674-5), afirmación especialmente significativa si tenemos en cuenta que es pronunciada por un poeta griego. Esta referencia a los descendientes de Eneas se concreta en los guías de esa nueva edad de oro. Si en Virgilio ese guía era un niño que había de nacer o un 
Augusto en la plenitud de su poder, en Opiano es el excelente padre

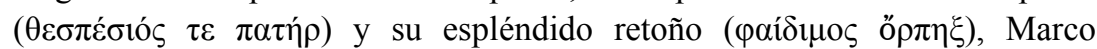
Aurelio y su hijo (II 682-3) ${ }^{48}$, quienes, tras épocas de alteración, han logrado por fin la paz. Y esa paz tiene un marco físico claramente definido por la mención de un imperio que se ha ido gestando desde «los antiguos reyes de los Ausonios» (II 676), con unos límites geográficos concretos (II 677-679): la parte occidental del imperio (tierra de iberos y celtas), el sur (la gran extensión de Libia) y los ríos que delimitan las fronteras del imperio al norte - Rin y Danubio - y al este - Éufrates ${ }^{49}$. Esas referencias geográficas precisas confirman, de algún modo, la filiación virgiliana en su tratamiento del mito de las edades, dado que otros autores latinos que no miran al pasado a la hora de situar un lugar en el que exista una nueva edad de oro - como hace Horacio en Serm. I 3,99-106 o en el Epodo XVI -, recurrieron a lugares geográficos utópicos, como las Islas Afortunadas ${ }^{50}$. Pues bien, según nos cuenta Opiano, ahora reina la paz en todo este ámbito geográfico descrito, tan conflictivo en otras épocas.

La difícil situación real que sabemos que existió en esas fronteras del imperio $^{51}$ durante el reinado de Marco Aurelio convertiría la afirmación de Opiano más en la expresión de un deseo que en la celebración de una realidad, lo que permitiría entrever una de las intencionalidades políticas del pasaje: la exaltación poética de un régimen que daba serios indicios de crisis. No obstante, sin descartar esta hipótesis - que, como veremos más adelante, se justifica por medio de la comparación con la línea de pensamiento político

48 No es ésta la única alusión a la pareja de soberanos - siempre representados como padre e hijo - como destinatarios de la instrucción de $H$. . Cf. también I 66 y 77 ss.; II 41 y IV 4 ss.

49 J. M. André, «La conception de l'Etat et de l'Empire dans la pensée gréco-romaine des deux premiers siècles de notre ère», $A N R W$ II, 30, 1, 1982, pp. 3-73, señala (pp. 55 ss.) que frente a la idea de un imperio ecuménico, que se desarrolla desde la época de Augusto - cf. la profecía de Júpiter en la Eneida I 278 ss., en donde habla de un imperio ilimitado en el tiempo y en el espacio -, se imponen limitaciones físicas basadas en barreras naturales. Así, Estrabón (XVII 3.25 ss.) habla de un imperio limitado por el Rín, el Danubio y el Éufrates. En este mismo sentido cf. Flavio Josefo, B.J. III 107.

50 Además, como señala Bauzá, ob. cit., pp. 113 ss., Horacio concibe este lugar de un modo pesimista, más propio de una huida, ya que (p. 115) «alude a un marco privilegiado como única salida frente a un momento histórico adverso como es el de las guerras fratricidas que asolaban al mundo romano»».

51 En particular con los graves problemas precisamente en el Danubio y en el Éufrates, que se mantuvieron después de la muerte de Marco Aurelio en el año 180 d.C. Un análisis detallado de los continuos conflictos fronterizos en P. Grimal, Marco Aurelio, Madrid, 1997, pp. 95-109 y 143-211. 
desarrollada a lo largo del siglo II d. C. -, la explicación más simple de esta nueva edad de oro alabada por Opiano está estrechamente ligada a las fechas que suelen barajarse para la publicación de la obra; es decir, entre los años 177 y 180. En efecto, el período de paz exaltado por el poeta coincidiría con el regreso triunfal de Marco Aurelio a Roma, tras ocho años de ausencia por culpa de sucesivas campañas militares. Justo en este momento (otoño del año 176 d.C.) asistimos a un período excepcional en el reinado de Marco Aurelio $^{52}$. Han sido sofocados temporalmente tanto los focos de tensión situados en las fronteras del imperio (Britania, Hispania, Egipto, Germania y las fronteras del Danubio y del Éufrates - coincidentes en gran medida con los confines geográficos señalados por Opiano), como eliminado el riesgo cierto de una guerra civil, provocada por la rebelión de los ejércitos romanos de Oriente al mando de Avidio Casio ${ }^{53}$. Esta situación, como ha estudiado P. Grimal ${ }^{54}$, tuvo su evidente reflejo en la acuñación de moneda a partir, precisamente, del año 176, con el predominio de divisas como concordia exercituum - en referencia al episodio protagonizado por Casio o Pax aeterna ${ }^{55}$. El emperador en este momento aparece, más que nunca, como protector del Estado. Marco Aurelio y Cómodo son proclamados imperatores por los soldados en noviembre del año 176 y juntos, el 23 de diciembre del mismo año, celebran en Roma su triunfo común. Este período excepcional en el ámbito político fue acompañado de la distribución de un congiario entre el pueblo ${ }^{56} \mathrm{y}$ de la condonación de las deudas particulares con el tesoro. Era como si el pasado quedase abolido y todo volviera a comenzar de nuevo. En resumen, era como si la edad de oro que Virgilio situó en los años de Augusto hubiera vuelto a producirse en este momento feliz del reinado de Marco Aurelio.

De hecho, como resalta el poeta como conclusión de todo el pasaje (II

52 Período que dura bien poco, porque, a mediados del año 178 d.C., Marco Aurelio habrá de dejar de nuevo - y ya de manera definitiva - la ciudad de Roma ante los nuevos problemas fronterizos en la zona de Germania. La presentación de la obra al emperador tendría que haberse llevado a cabo, por lo tanto, en el período que va desde finales del 176 a mediados del 178 d.C.

53 Cf. P. Grimal, ob. cit., p. 188 y ss.

54 Cf. P. Grimal, ob. cit., p. 201 y ss.

55 Cf. H. Mattingly (y otros), Roman Imperial Coinage, vol III (Antoninus Pius to Commodus), Londres, 1930, pp. 638 y 646.

56 Cf. Dion Casio, LXXI 32. 
680-681), lo relevante, sobre todo, es que, en el momento actual (vûv), la Justicia comparte el hogar y la casa con los hombres. De este modo, el poeta cilicio, partiendo del tópico hesiódico de la falta de justicia en el mundo de los peces y en el de los hombres de estirpe de hierro, lo reconvierte, dotándolo de un marcado carácter político, en un medio de alabar y enaltecer el justo reinado de Marco Aurelio sobre el mundo contemporáneo, que, según Opiano, representa una nueva edad de oro en la que el emperador ha conseguido la paz y ha acabado con la «Discordia pródiga en dolores» (II 668: "E $\rho 1 \varsigma \dot{\alpha} \lambda \gamma \varepsilon \sigma i ́ \delta \omega \rho \rho \varsigma)$. Esta idea, si tenemos en cuenta el marco de la poesía didáctica greco-latina previa, tiene un valor evidente. La alabanza a ese poder imperial que ha traído la paz no es sólo una referencia laudatoria más de las muchas que contienen este tipo de poemas en época romana, cuando el destinatario de la instrucción - el princeps - se coloca por encima del poeta. Pensamos que, teniendo en cuenta los datos históricos, va más allá de la simple adulación hacia el elevado destinatario de la instrucción didáctica, y que el poeta ha utilizado el ejemplo negativo que proporciona el predatorio y cruel mundo de los peces para resaltar la aportación del poder imperial a la pacificación y finalización de la citada discordia en un imperio que, no obstante, ya entraba en crisis. Este último término es clave, ya que pone de manifiesto la importancia de algo que no se cita directamente en este pasaje del poema ${ }^{57}$, pero cuya importancia es resaltada de manera continuada: la idea de concordia o ó $\mu$ óvor $\alpha$ como fuerza integradora y como medio de superar los períodos de crisis, una idea de enorme peso en la cultura griega y romana.

2.5. En este sentido, pensamos además que no sólo influyó sobre Opiano la tradición literaria previa y la decisiva figura de Virgilio, que permitía contemplar el presente como una vuelta a los años dorados, sino que el autor enfocó y reinterpretó el contenido ictiológico desarrollado en el libro II en la misma dirección que algunos de los prosistas más destacados de la Segunda Sofística, como Dión de Prusa o Elio Aristides, quienes en sus discursos concedieron gran importancia a la cuestión de acabar con las

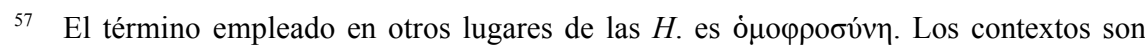
muy significativos: I 415 (poder de Zeus, que ha unido a todos los seres con un vínculo de concordia) V 444 (relación de concordia entre los hombres y los delfines, los reyes del mar) y V 563 (hombres que pescan delfines, quebrantando la mutua concordia). Con respecto a este término en época imperial, cf. A.P. VII 551, donde se emplea el mismo término para referirse a la Concordia personificada. 
disputas y de propugnar la concordia en los dos sentidos del término: concordia nacional opuesta a $\pi \delta ́ \lambda \varepsilon \mu \circ \varsigma$ y concordia social opuesta a $\sigma \tau \alpha ́ \sigma ı \zeta$. El tema de la concordia suscitó el interés y la preocupación de los autores de la Segunda Sofística, como han estudiado $\operatorname{Sirago}^{58}$ y $\mathrm{Bravo}^{59}$, ya sea por la necesidad de afrontar una situación explosiva que comenzaba a expandirse entre las clases humildes, ya como consecuencia de las frecuentes rivalidades entre ciudades.

Así, para Dión de Prusa ${ }^{60}$, la ciudad concorde es similar a una casa bien administrada. Lo que hay que alabar en los hombres ${ }^{61}$ es la disciplina

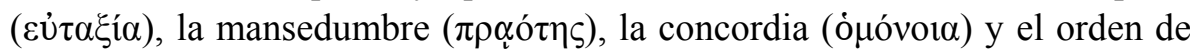

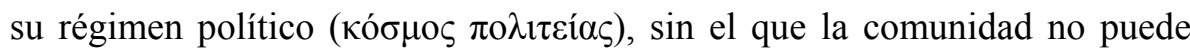
existir $^{62}$, lo que lleva a Dión a decir que la ley es para las ciudades un instrumento más útil que el timón para los barcos ${ }^{63}$. En este contexto, el sofista propone el ejemplo de ciertos animales terrestres - descarta los marinos por la "mala prensa" que hemos visto que arrastraban -, como las hormigas $^{64}$, los pájaros ${ }^{65}$, o las abejas ${ }^{66}$, que constituyen un modelo de conducta. Elio Aristides, por su parte, en su discurso $A$ los rodios 22 ss., afirma que obedecer a uno más poderoso es ley de naturaleza y que desobedecerlo no lleva en modo alguno a la libertad, sino a la anarquía;

58 V. A. Sirago, «La seconda sofistica come espressione culturale», $A N R W$ II 33.1, 1989, pp. 50-66

59 A. Bravo García, «Notas sobre el tema de la concordia en Dión de Prusa», Habis 4, 1973, pp. 81-92.

60 Cf. M. J. Hidalgo de la Vega, El intelectual, la realeza y el poder político en el imperio romano, Salamanca, 1995, quien ha estudiado las bases teóricas de la legitimaciòn del poder real del emperador y la elaboración del correspondiente speculum principis. En concreto, en las pp. 59-103 analiza los discursos Sobre la realeza de Dión de Prusa.

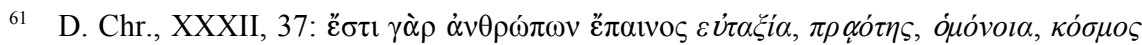

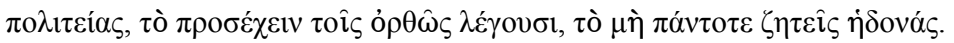

62 Cf. D. Chr., XXXVI 20 y 31

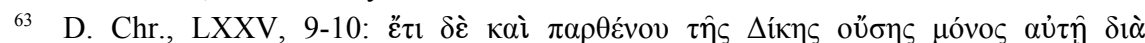

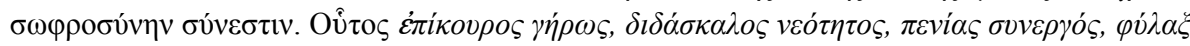

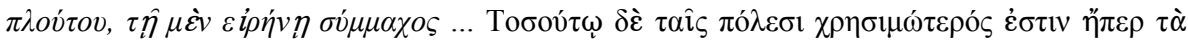

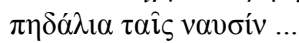

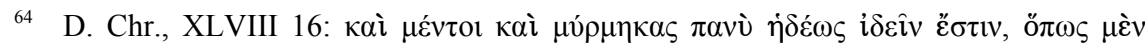
оікоиิ

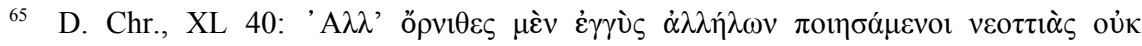

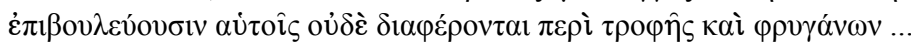

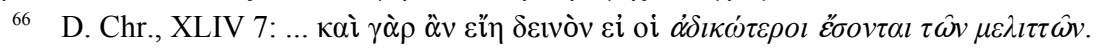


afirmación esta última que, precisamente, presenta claras concomitancias con el comienzo del libro II de Opiano, donde se defiende la sumisión de los hombres a un poder divino, que regula y dirige todo desde lejos, pero estando muy cerca ( $H$. II 7-8); y el que un destino inmutable obligue a los hombres a prestar obediencia (H. II 8-9).

Esta necesidad de orden y concordia expresada por los autores de los dos primeros siglos d. C. tiene dos causas principales. En primer lugar, surge por influencia de la línea de pensamiento oficial, el estoicismo, que, en las manos de los nuevos sofistas y poetas, se puso al servicio del orden constituido y de la paz pública. Así, bajo el reinado de Marco Aurelio, se extiende la idea de un imperio mundial ${ }^{67}$, regido por la fuerza y por la ley; y de una sociedad piramidal cuyo vértice es el emperador, preocupado por la salvación de todos los hombres. Con el objetivo de difundir y fortalecer esta idea, la cultura griega es puesta al servicio de la realidad política del momento. En segundo lugar, el comienzo de una nueva crisis en el imperio, con problemas en la frontera y con un progresivo empobrecimiento interior $^{68}$, justifica esa preocupación por el orden y la concordia. En este sentido, el elogio de la concordia entre las ciudades y los hombres servía para sancionar un orden constituido que comenzaba a verse amenazado ${ }^{69}$.

Ahora bien, mientras autores como Dión de Prusa tratan estos asuntos con un objetivo exclusivamente moralizante, Opiano es un poeta que sigue la línea iniciada por Virgilio, con la intención de defender una postura más política que ética ${ }^{70}$. En el epílogo del libro II Opiano afirma que esa paz y justicia no son una meta, sino una gracia otorgada por la divinidad al

${ }^{67}$ Cf. H. II 675: $\gamma \alpha i ̂ \alpha v$.

68 Cf. V. A. Sirago, Involuzione politica e spirituale nell' Impero del II Secolo, Nápoles, 1974.

69 Hasta tal punto está presente esa amenaza en los autores griegos del período que, por

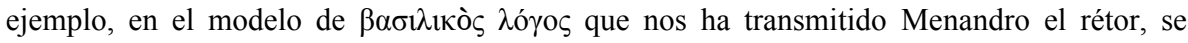
destaca de manera preferente el papel del emperador como pacificador, defensor y guardián del orden romano (cf. 377.15-17) frente a otras características como la de simple benefactor de ciudades.

70 Cf. J. Ferguson, «Homonoia», en Moral Values in the Ancient World, Londres, 1958,

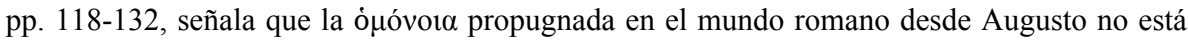
unida a la idea de una ciudad (o ciudades como en el caso de Dión de Prusa) o de un pueblo (como en el caso de Plutarco: los griegos han de renunciar a la rebelión y fomentar la tolerancia), sino que se refiere a la inconmensurable majestad de la Paz Romana de la que habla Plinio (N.H., XII 2; XXVII 3) y que incluso alaban los apologetas cristianos. 
emperador ${ }^{71}$. Pensamos, pues, que la intención última del poeta va más allá de hacer un cumplido a la autoridad imperial o de ofrecer una enseñanza moral: el objetivo del libro II de Haliéuticas es realizar una exaltación del régimen establecido. En este sentido, Opiano adopta una postura más cercana a la defendida por Elio Aristides, en su discurso Sobre la concordia ${ }^{72}$, donde deja claro que la ciudad de Roma es la que domina la tierra, o en su discurso $A$ Roma $^{73}$, donde señala que el marco político impuesto por los emperadores romanos como el mejor de los posibles ${ }^{74}$, hasta el punto de contraponerlo incluso a los vanos intentos previos llevados a cabo por los griegos para conseguir la paz y la unión. Así pues, ambos griegos se oponen tanto a aquellos compatriotas que no encontraban un cauce adecuado para sus pretensiones políticas, como a los que miraban el pasado de Grecia con cierta añoranza ${ }^{75}$. Para Opiano, como poeta griego sumiso al poder romano, la única opción defendible es mantener el status quo del imperio y mucho más ante el presente momento de gloria de Marco Aurelio y, por extensión, de Cómodo, su futuro sucesor.

3. En conclusión, creemos haber demostrado que Opiano de Cilicia, en el libro II de las Haliéuticas, retoma el tema tradicional de "las edades del mundo" y lo reconvierte bajo la influencia de la tradición poética previa, en la que desempeña un papel decisivo el nuevo enfoque dado por Virgilio;

71 Cf. $H$. II 674-5 y 686-9.

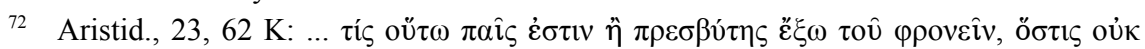

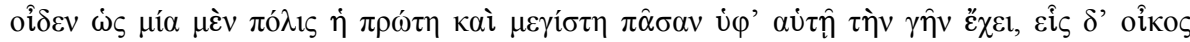

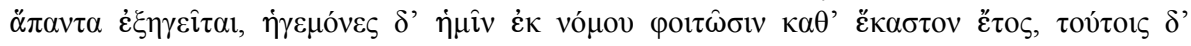

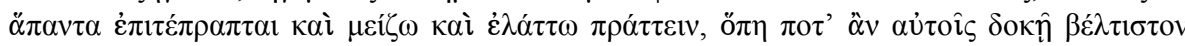

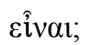

73 El tema del Discurso a Roma es el de la armonía universal en el mundo entero y el modelo que supone Roma, lo que lleva al sofista a compararlo (14-70) con imperios precedentes como el persa o el macedónico y a estudiar el imperio presente (89-107) como un organismo armónico. Cf. R. Klein, Die Romrede des Aelius Aristides, Darmstadt, 1981. J. Palm, Rom, Römertum und Imperium in der griechischen Literatur der Kaiserzeit, Lund, 1959.

74 Cf. Aristid., 26, $103 \mathrm{~K}$ : del mismo modo que Zeus puso fin al desorden previo e inició un nuevo período en el Olimpo, así hizo Roma con su imperio. Cf. G. Barker, From Alexander to Constantine, Oxford, 1966, pp. 214-5, sobre el César como restitutor orbis, bajo cuyo gobierno se inaugura una nueva Edad de Oro.

75 Cf. A. D. Macro, «The Cities of Asia Minor under the Roman Empire», ANRW 7, 2, 1980, p. 687 y E. L. Bowie, «Greek and their Past in the Second Sophistic», en M. I. Finley (ed.), Studies in Ancient Society, Londres, 1974, pp. 166-205. 
Opiano selecciona a partir de sus fuentes en prosa los datos que considera útiles para desarrollar el tema de la ausencia de justicia en el mundo marino, constituyendo un ejemplo de conjunción de forma y contenido; y el resultado obtenido, la alabanza del poder constituido, del emperador que, con sus victorias externas e internas, ha conseguido instaurar una nueva aurea aetas en la que se ha puesto fin a la discordia y se ha restituido la justicia, coincide con una de las preocupaciones más importantes de los pensadores del siglo II d. de C. Según eso, retomando la tesis de Effe sobre la finalidad moralizante del poema y la de James sobre un interés únicamente estético del mismo, hemos comprobado que, al menos en el libro II de Haliéuticas, existe un objetivo que va más allá de lo meramente estético - de una poesía por la poesía -, y que este objetivo es más de índole política que moralizante.

Así pues, hemos de concluir que, por lo menos en lo que se refiere al libro II, el poema de Opiano ni es solamente un ejercicio de erudición poética, ni su finalidad última es simplemente la de fustigar los vicios de una sociedad de hombres que pueda parangonarse con la de los peces. Por lo demás, pasajes fundamentales de las Haliéuticas también están concebidos como un medio de alabanza y justificación del poder del emperador ${ }^{76}$. En definitiva, se trata de una obra escrita en griego que encontró su perfecto acomodo en una época, la de los Antoninos, en la que la retórica y la poesía griega gozaron de gran aceptación, y en la que el objetivo final de sofistas y poetas fue alcanzar el favor imperial.

\footnotetext{
76 Cf. en este sentido el proemio de Cinegéticas de Opiano de Apamea, donde, según I. Opelt («Zum Kaiselkult in der griechischen Dichtung», RhM 103, 1960, p. 53), estamos ante un perfecto ejemplo de culto al emperador por parte de un poeta griego. Cf. además los trabajos de G. W. Bowersock, «Greek Intellectuals and the Imperial Cult in the Second Century A.D.» (pp. 179-212) y K. Thraede, «Die Poesie und der Kaiserkult» (especialmente las pp. 274-5), en W. de Boer (ed.), Le culte des souverains dans l'empire romain (Fondation Hardt XIX), Vandoeuvres-Ginebra, 1973.
} 